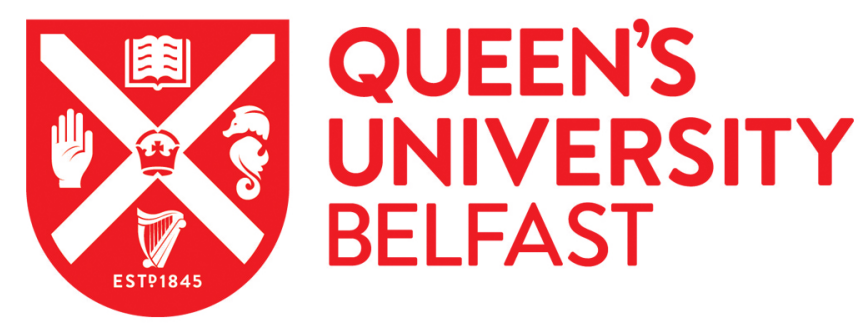

\title{
Meal skipping habits and nutritional status among Ghanaian students living in Korea
}

Dzatse, M. E., Kim, E., Kim, H., Kim, H., Vijayakumar, A., \& Chang, N. (2017). Meal skipping habits and nutritional status among Ghanaian students living in Korea. Journal of Nutrition and Health, 50(4), 376-382. https://doi.org/10.4163/jnh.2017.50.4.376

Published in:

Journal of Nutrition and Health

Document Version:

Publisher's PDF, also known as Version of record

Queen's University Belfast - Research Portal:

Link to publication record in Queen's University Belfast Research Portal

Publisher rights

(C) 2017 The Authors.

This is an Open Access article distributed under the terms of the Creative Commons Attribution Non-Commercial License

(http://creativecommons.org/licenses/by-nc/3.0/) which permits unrestricted non-commercial use, distribution, and reproduction in any medium, provided

the original work is properly cited.

\section{General rights}

Copyright for the publications made accessible via the Queen's University Belfast Research Portal is retained by the author(s) and / or other copyright owners and it is a condition of accessing these publications that users recognise and abide by the legal requirements associated with these rights.

Take down policy

The Research Portal is Queen's institutional repository that provides access to Queen's research output. Every effort has been made to ensure that content in the Research Portal does not infringe any person's rights, or applicable UK laws. If you discover content in the Research Portal that you believe breaches copyright or violates any law, please contact openaccess@qub.ac.uk. 


\title{
Meal skipping habits and nutritional status among Ghanaian students living in Korea*
}

\author{
Monica E. Dzatse $^{* *} \cdot$ Eun-kyung Kim ${ }^{* *} \cdot$ Hyesook Kim $\cdot$ Hyejin Kim $\cdot$ Aswathy Vijayakumar $\cdot$ Namsoo Chang ${ }^{\dagger}$ \\ Department of Nutritional Science and Food Management, Ewha Womans University, Seoul 03760, Korea
}

\begin{abstract}
Purpose: The consistent rise in the number of foreign students in Korea demands an accurate and detailed investigation into their dietary practices and nutritional status. For these international students, assimilation into new cultures can be stressful. The influence this process may have on dietary behaviors as well as overall health cannot be overlooked. Methods: The researchers in this study sought to investigate the nutritional status and dietary practices of Ghanaian students studying in Korea. A total of 81 Ghanaian male students with an average age of $29.4 \pm 4.0$ years were sampled between May and June 2016. Investigations were carried out on the general characteristics of the participants, their daily food and nutrient intakes using a 24-h dietary recall method, meal skipping practices, and the nutritional quality of their diets based on their meal skipping habits. Results: The study revealed that the daily nutrient intake of subjects did not fully meet the daily recommended nutrient intake (RNI) established by Ghanaian Ministry of Health and the World Health Organization (WHO) and Food and Agriculture Organization (FAO), particularly for energy, calcium, iron, zinc, and vitamin B2 requirements. The Nutrient Adequacy Ratio (NAR) for calcium was very low, posing a deficiency risk to the participants. Meal skipping practices among participants changed significantly after arriving in Korea. The study also compared the diet quality indicators (Nutrient Adequacy Ratio and Mean Adequacy Ratio) of those who skipped meals $\geq 7$ times/week with those who skipped meals $<7$ times/week. Participants who skipped meals $\geq 7$ times/week were shown to have lower dietary intakes of vitamins B1 and B2 than those who skipped meals $<7$ times/week. Conclusion: Ultimately, the study found that meal skipping among Ghanaian students was common, and their daily nutrient intakes did not meet the set dietary standards. Those who skipped meals $\geq 7$ times/week had lower dietary intakes of vitamins B1 and B2 than those who skipped meals $<7$ times/week. Based on our study findings, we recommend that nutrition education should be organized for the Ghanaian student community in Korea using our results as a template to draw up a nutrition program that is culturally appropriate.
\end{abstract}

KEY WORDS: Ghanaian students, meal skipping, food and nutrient intake, nutritional status

\section{Introduction}

The induction of the 'Study Korea Project' has seen a dramatic increase in the number of international students in Korea. ${ }^{1,2}$ Relocation, such as from a rural to an urban setting and vice versa, can cause significant changes to an individual's lifestyle patterns, particularly, dietary and food habits. ${ }^{3}$ Several studies have been conducted on dietary practices and acculturation of migrants and international students. ${ }^{4-8}$ For international students, the process of adaptation to new cultures and the influence of external factors on their dietary behavior cannot be trivialized. Negative changes in dietary behaviors, for instance decreased consumption of fruits and vegetables, increased consumption of alcohol, sweets, lipids, and high energy intake, have been reported. Also, irregular eating habits, such as skipping meals, particularly breakfast, and increased snacking at irregular times, have been widely mentioned. ${ }^{4-8}$ A study conducted among Chinese students studying in South Korea revealed that regular breakfast consumption by the students decreased from 43.0 to $23.2 \%$ after migration from China to the Republic of Korea. In addition, the subjects who had three square meals a day also decreased from $80.3 \%$ in China to $49.3 \%$ in South Korea. Furthermore, their vegetable consumption also declined, from $44.4 \%$ in China to $24.6 \%$ in South Korea. ${ }^{8}$ In Nigeria,

Received: February 27, 2017 / Revised: March 6, 2017 / Accepted: July 24, 2017

*This study was supported by Brain Korea 21 Plus.

** These authors contributed equally to this work.

${ }^{\dagger}$ To whom correspondence should be addressed.

tel: +82-2-3277-3468, e-mail: nschang@ewha.ac.kr 
students who were staying in boarding houses were found to be deficient in protein $(15 \%)$ and vitamin $\mathrm{C}(25 \sim 80 \%)$ among various age groups. ${ }^{9}$

There are several potential challenges to overcome when relocating to a foreign country, such as acculturative stress (i.e., stress emanating from life changes in the process of assimilating new cultures). International students, unlike other immigrants, encounter a unique situation because they may be exposed to relatively novel experiences and often have to confront the reality of being physically apart from their parents, as well as other relatives, for the first time. ${ }^{10-12}$ Therefore, it is imperative that a detailed and accurate assessment of their dietary habits and daily nutrient and food intakes are determined so that the appropriate nutritional recommendations and education can be provided.

The National Statistical Office recently stated that there has been an increase in the number of Ghanaian students living in Korea. ${ }^{13}$ However, lack of detailed information about the lifestyle characteristics of the Ghanaian students in Korea may result in educational initiatives or interventions by nutrition educators, that may be culturally inappropriate and may be detrimental to their health.

Therefore, the objective of this study was to investigate the current dietary intake of Ghanaian students living in South Korea and to compare their meal skipping habits before and after migrating to South Korea.

\section{Methods}

\section{Study subjects}

Participants in this study were Ghanaians studying in South Korea. A total of 81 male students were recruited from universities in Seoul, Suwon, Cheonan, Daejon, Daegu and Pusan between May and June 2016. As inclusion criteria, the participants were supposed to have been residents in South Korea for at least 1 month and should have been living in Ghana prior to their relocation to Korea. Involvement in the study was exclusively voluntary. Therefore, respondents were at liberty to withdraw from the study at any time. This study protocol was approved by the Institutional Review Board (115-12) at Ewha Womans University, Seoul, Republic of Korea.

\section{General characteristics}

A well-constructed, self-administered questionnaire was deployed to gather information on the demographic, socio- economic and health-related profiles of the participants, through a face-to-face interview conducted by trained researchers, according to standard protocols. The questionnaire was originally written in Korean and, therefore, had to be translated into English. Data on height $(\mathrm{cm})$ and weight $(\mathrm{kg})$, Korean speaking abilities, family income $(\leq 1,500$ and $\geq 2,000$ USD), duration of stay in Korea (months), as well as cigarette smoking (yes/no) and alcohol intake (yes/ no), both in Ghana and Korea, were collected. The body mass index (BMI) was calculated from the weight and height data $\left(\mathrm{kg} / \mathrm{m}^{2}\right)$. Korean speaking abilities were categorized as good (able to understand and hold a conversation in Korean), average (difficulty understanding and holding a conversation in Korean) and poor (cannot understand and hold a conversation in Korean).

\section{Dietary intake survey}

Well-trained researchers collected dietary intake records using a single $24 \mathrm{~h}$ dietary recall surveys conducted in single face-to-face interviews. One of the interviewers was fluent in the language of Ghana. All interviewers and study participants were also fluent in English. Therefore, no language barrier was present. Participants reported all foods and drinks consumed during the previous day. Books containing pictures of cooked foods and raw ingredients, in various portions that are normally consumed on a daily basis, were displayed to the participants to ensure a nearaccurate measurement of what they ate. To reduce variations between weekdays and weekends, the interview was conducted from Tuesday to Saturday. To analyze the intake of foods and nutrients among the participants and ensure that traditional recipes were included, all foods and their ingredients were checked and analyzed together by Ghanaian and Korean researchers and included in the Computer Aided Nutritional analysis program 4.0 (Canpro 4.0, The Korean Nutrition Society).

\section{Diet quality assessment}

The Nutrient Adequacy Ratio (NAR) was calculated for 11 nutrients (protein, calcium, iron, zinc, vitamin A, vitamin $\mathrm{B} 1$, vitamin $\mathrm{B} 2$, vitamin $\mathrm{B} 6$, folate, niacin, and vitamin C) using the dietary guidelines for Ghanaians and the WHO/FAO dietary guidelines stipulated for various populations. The standard RNI values for protein, iron, zinc, vitamin $\mathrm{A}$, folate, and vitamin $\mathrm{C}$ were based on the Dietary Guidelines for Ghana ${ }^{14}$ and the RNI for calcium, 
vitamin $\mathrm{B}$ 1, vitamin $\mathrm{B} 2$, vitamin $\mathrm{B} 6$, and niacin was based on WHO/FAO guidelines. ${ }^{15}$ The Mean Adequacy Ratio (MAR) was computed as the averages of all NARs divided by the number of nutrients.

NAR $=$ Dietary intake of the nutrient / RNI or RDA of the nutrient

MAR $=\Sigma$ NAR (each nutrients' NAR)/Number of nutrients

\section{Measurement of meal skipping habits}

To assess meal skipping habits, subjects were instructed to write down the number of times they typically skip meals per week in Korea. Subjects were divided into two categories, those who skipped meals $<7$ times/week, and those who skipped meals $\geq 7$ times/week. Nutrient intake status was compared between the two categories.

\section{Statistical analysis}

All data were presented as means and standard deviations (SD) for continuous variables, and frequency and percentages for categorical variables. Student's t-test was used to determine the differences between NAR and MAR according to meal skipping habits. All reported probability tests were two-sided, and the difference was considered statistically significant $p<0.05$. SAS 9.4 software was used for all statistical analysis.

\section{Results}

\section{General characteristics}

The general characteristics of the study subjects are summarized in Table 1. The mean age of the study subjects was $29.4 \pm 4.0$ years. The mean length of stay in Korea for the participants was $19.7 \pm 18.2$ months. Among the study subjects, $75.3 \%$ had average proficiency in Korean language, and $98.8 \%$ received a scholarship to fund their studies. Only $14.8 \%$ stayed in a dormitory that provided meals, and $59.3 \%$ stayed in apartments.

\section{Daily food intake based on food groups}

The daily food intakes of the subjects obtained by a 1-day 24-h dietary recall interview are presented in Table 2 . The mean total food intake was $1,202.4 \pm 361.2 \mathrm{~g}$. The daily foods consumption were $373.9 \mathrm{~g}$ for cereal and cereal products, $226.7 \mathrm{~g}$ for vegetables, $96.0 \mathrm{~g}$ for fruits, $0.5 \mathrm{~g}$ for nuts and seeds, and $105.5 \mathrm{~g}$ for milk and milk products.
Table 1. General characteristics of the study population

\begin{tabular}{|c|c|}
\hline Characteristics & Total $(n=81)$ \\
\hline Age (years) & $29.4 \pm 4.0^{11}$ \\
\hline Weight $(\mathrm{kg})^{2)}$ & $69.0 \pm 10.0$ \\
\hline Height $(\mathrm{cm})^{2)}$ & $173.8 \pm 8.9$ \\
\hline Body mass index $\left(\mathrm{kg} / \mathrm{m}^{2}\right)^{3)}$ & $23.0 \pm 3.2$ \\
\hline Length of stay in Korea (months) & $19.7 \pm 18.2$ \\
\hline \multicolumn{2}{|l|}{ Korean proficiency } \\
\hline Good & $13(16.1)$ \\
\hline Average & $61(75.3)$ \\
\hline Poor & $7(8.6)$ \\
\hline \multicolumn{2}{|l|}{ Household income USD } \\
\hline$\leq 1,500$ & $58(71.6)$ \\
\hline$\geq 2,000$ & $23(28.4)$ \\
\hline Alcohol drinking & $12(15.2)$ \\
\hline Cigarette smoking & - \\
\hline Nutritional supplement user & $3(3.8)$ \\
\hline \multicolumn{2}{|l|}{ Type of community in Ghana } \\
\hline Urban & $69(85.1)$ \\
\hline Suburb & $11(13.6)$ \\
\hline Rural & $1(1.2)$ \\
\hline \multicolumn{2}{|l|}{ Residential type } \\
\hline Apartment & $48(59.3)$ \\
\hline Dormitory without food & $21(25.9)$ \\
\hline Dormitory with food & $12(14.8)$ \\
\hline \multicolumn{2}{|l|}{ Funding for studies } \\
\hline Scholarship & $80(98.8)$ \\
\hline Self-funding & $1(1.2)$ \\
\hline Current disease condition & - \\
\hline
\end{tabular}

1) Values are presented as mean $\pm S D$ or frequency (\%). 2) Body weight and height given by subjects 3) BMl: Body mass index was calculated as body weight $(\mathrm{kg}) /$ height $^{2}(\mathrm{~m})$.

Table 2. Daily food intakes of subjects by food groups ${ }^{1 /}$

\begin{tabular}{lc}
\hline \multicolumn{1}{c}{ Food groups $(\mathrm{g} / \mathrm{d})$} & Total $(\mathrm{n}=81)$ \\
\hline Cereal and cereal products & $373.9 \pm 103.7$ \\
Potatoes and starch products & $22.6 \pm 62.6$ \\
Vegetables & $226.7 \pm 155.7$ \\
Fruits & $96.0 \pm 165.6$ \\
Seaweed & $0.8 \pm 4.4$ \\
Mushrooms & $0.5 \pm 2.3$ \\
Soy bean and bean products & $29.7 \pm 72.9$ \\
Nuts and seeds & $0.5 \pm 2.7$ \\
Eggs and egg products & $35.1 \pm 45.0$ \\
Meats and meat products & $99.7 \pm 71.1$ \\
Fish and fish products & $35.9 \pm 61.2$ \\
Milk and milk products & $105.5 \pm 153.5$ \\
Beverages & $82.1 \pm 183.8$ \\
Sugar and sugar products & $5.9 \pm 10.8$ \\
Fats and oils & $24.6 \pm 22.5$ \\
Total food intake & $1,202.4 \pm 361.2$ \\
\hline
\end{tabular}

1) Values are presented as mean \pm SD. 


\section{Daily nutrient intakes}

The mean daily nutrient intakes of the subjects and the proportion who did not meet the RNIs, based on Dietary Guidelines for Ghana and the WHO/FAO guidelines, are shown in Table 3. The mean daily energy intake was $2,289.6 \pm 548.9 \mathrm{kcal}$. The mean energy distribution for carbohydrate: protein: fat was 65.8: 12.2: 22.0. The proportion of subjects whose nutrient intakes did not meet the RNIs were highest for energy (92.6\%) and lowest for protein $(14.8 \%)$. None of the study participants met the daily dietary requirement for calcium.

Table 3. Daily nutrient intake of subjects ${ }^{11}$

\begin{tabular}{|c|c|c|}
\hline Nutrient & Nutrient intake & Below RN|2) \\
\hline Energy (kcal/d) & $2,289.6 \pm 548.9$ & $75(92.6)$ \\
\hline Protein $(\mathrm{g} / \mathrm{d})$ & $69.1 \pm 17.8$ & $12(14.8)$ \\
\hline Fat $(g / d)$ & $55.1 \pm 21.4$ & - \\
\hline Carbohydrate (g/d) & $373.9 \pm 10.3 .7$ & - \\
\hline Dietary fiber $(\mathrm{g} / \mathrm{d})$ & $14.6 \pm 5.7$ & - \\
\hline Calcium (mg/d) & $315.2 \pm 205.7$ & $81(100.0)$ \\
\hline $\operatorname{Iron}(\mathrm{mg} / \mathrm{d})$ & $11.4 \pm 3.9$ & $62(76.5)$ \\
\hline $\operatorname{Zinc}(\mathrm{mg} / \mathrm{d})$ & $11.1 \pm 3.6$ & $70(86.4)$ \\
\hline Vitamin A ( $\mu g$ RE/d) & $552.4 \pm 414.8$ & $52(64.2)$ \\
\hline Vitamin E (mgaTE/d) & $24.9 \pm 12.6$ & - \\
\hline Vitamin Bl (mg/d) & $1.2 \pm 0.3$ & $37(45.7)$ \\
\hline Vitamin B2 (mg/d) & $1.0 \pm 0.4$ & $63(77.8)$ \\
\hline Vitamin B6 (mg/d) & $1.5 \pm 0.6$ & $34(42.0)$ \\
\hline Folate ( $\mu \mathrm{g}$ DFE/d) & $363.7 \pm 143.1$ & $56(69.1)$ \\
\hline Niacin (mg NE/d) & $15.5 \pm 6.7$ & $48(59.3)$ \\
\hline Vitamin C (mg/d) & $59.8 \pm 42.8$ & $34(42.0)$ \\
\hline \multicolumn{3}{|l|}{ Energy distribution } \\
\hline \% Carbohydrate & $65.8 \pm 6.7$ & \\
\hline$\%$ Protein & $12.2 \pm 2.1$ & \\
\hline$\%$ Fat & $22.0 \pm 7.3$ & \\
\hline
\end{tabular}

$\begin{array}{lll}\text { 1) Values are presented as mean } \pm S D \text { or frequency (\%). } & \text { 2) The }\end{array}$ standard values of RNI for Energy, protein, iron, zinc, vitamin A, vitamin $C$, and folate was based on Dietary Guidelines for Gha$\mathrm{na}^{14}$ and RNI for calcium, vitamin B1, vitamin B2, niacin, vitamin B6 was based on WHO/FAO guideline. 15

\section{Dietary habit status according to meal skipping}

As shown in Table 4, the frequency of the meal skipping increased after coming to Korea among subjects who skipped meals $\geq 7$ times/week. The frequency of breakfast skipping increased from $2.6 \pm 2.9$ times/week, while in Ghana, to $5.2 \pm 2.3$ times/weeks, while in Korea ( $p=$ $0.0004)$. There was also a significant increase in the meal skipping frequency for lunch $(\mathrm{p}=0.0164)$ and dinner $(\mathrm{p}=$ $0.0319)$. Inadequate time was cited as the main reason for skipping meals in both groups.

\section{NAR and MAR according to meal skipping habit}

NAR and MAR of participants who skipped meals $\geq 7$ times/week and $<7$ times/week was shown in Table 5. The subjects who skipped meals $\geq 7$ times/week had significantly lower NAR for vitamin B1 ( 0.83 vs. $0.92, \mathrm{p}=$ $0.0180)$ and vitamin $B 2(0.61$ vs. $0.73, p=0.0433)$ compared to those who skipped meals $<7$ times/week. NAR for calcium was the lowest in both subjects, those who skipped meals $\geq 7$ times/week (0.28) and those who

Table 5. NAR and MAR according to meal skipping ${ }^{1 /}$

\begin{tabular}{lcc}
\hline & $<7$ times/week $(n=56)$ & $\geq 7$ times/week $(n=25)$ \\
\hline Protein & $0.99 \pm 0.03$ & $0.96 \pm 0.09$ \\
Vitamin A & $0.67 \pm 0.30$ & $0.78 \pm 0.28$ \\
Vitamin B1 & $0.92 \pm 0.15^{*}$ & $0.83 \pm 0.17$ \\
Vitamin B2 & $0.73 \pm 0.24^{*}$ & $0.61 \pm 0.25$ \\
Niacin & $0.84 \pm 0.19$ & $0.81 \pm 0.22$ \\
Vitamin B6 & $0.90 \pm 0.16$ & $0.88 \pm 0.16$ \\
Folate & $0.80 \pm 0.20$ & $0.83 \pm 0.20$ \\
Vitamin C & $0.80 \pm 0.27$ & $0.83 \pm 0.28$ \\
Calcium & $0.33 \pm 0.21$ & $0.28 \pm 0.21$ \\
Iron & $0.78 \pm 0.19$ & $0.73 \pm 0.22$ \\
Zinc & $0.74 \pm 0.19$ & $0.68 \pm 0.20$ \\
MAR & $0.77 \pm 0.13$ & $0.75 \pm 0.12$ \\
\hline
\end{tabular}

1) Values are presented as mean $\pm S D$.

*Differences according to meal skipping determined by t-test

Table 4. Dietary habit status according to meal skipping ${ }^{1)}$

\begin{tabular}{|c|c|c|c|c|c|c|}
\hline \multirow{2}{*}{ Variables } & \multicolumn{2}{|c|}{$<7$ times/week $(n=56)$} & \multirow{2}{*}{$p^{2)}$} & \multicolumn{2}{|c|}{$\geq 7$ times/week $(n=25)$} & \multirow{2}{*}{$\mathrm{p}^{2)}$} \\
\hline & In Ghana & In Korea & & In Ghana & In Korea & \\
\hline \multicolumn{7}{|c|}{ Frequency of skipping (n/wk) } \\
\hline Breakfast & $1.7 \pm 1.9$ & $2.0 \pm 1.9$ & 0.1479 & $2.6 \pm 2.9$ & $5.2 \pm 2.3$ & 0.0004 \\
\hline Lunch & $0.6 \pm 1.2$ & $0.5 \pm 1.2$ & 0.7325 & $0.8 \pm 1.2$ & $1.8 \pm 2.0$ & 0.0164 \\
\hline Dinner & $0.1 \pm 0.4$ & $0.2 \pm 0.5$ & 0.3218 & $0.6 \pm 1.2$ & $1.3 \pm 1.7$ & 0.0319 \\
\hline \multicolumn{7}{|l|}{ Reasons for skipping } \\
\hline Inadequate time & \multicolumn{2}{|c|}{$35(77.8)$} & \multicolumn{4}{|c|}{$20(80.0)$} \\
\hline Not tasty & \multicolumn{2}{|c|}{$2(4.4)$} & \multicolumn{4}{|c|}{$2(8.0)$} \\
\hline Others & \multicolumn{2}{|c|}{$8(17.8)$} & \multicolumn{4}{|c|}{$3(12.0)$} \\
\hline
\end{tabular}

$\begin{array}{lll}\text { 1) Values are presented as mean } \pm S D \text { and frequency (\%). } & \text { 2) Differences in meal skipping determined by paired t-test }\end{array}$ 
skipped meals $<7$ times/week (0.33). NAR for protein, niacin, vitamin B6, calcium, iron, and zinc and MAR were also lower among subjects who skipped meals $\geq 7$ times/ week than those who skipped meals $<7$ times/week, but not statistically significant.

\section{Discussion}

The purpose of this study was to examine the meal skipping habits and assess the nutritional status of Ghanaian students currently staying in Korea. In our study, the daily food intake was $1,202.04 \pm 361.2 \mathrm{~g}$, of which, plant-based food constituted $74.5 \%$ and animal-based food constituted $25.5 \%$. Cereal and cereal products were the most consumed plant food, whereas milk and milk products were the most consumed animal food. A study of mothers of childbearing age in the Eastern Region of Ghana showed that $95.3 \%$ of the respondents consumed fish daily, while 37.8 and $53 \%$ consumed meat and milk, respectively, on a weekly basis. ${ }^{16}$ Similarly, another study, comparing the food intake of Ghanaians staying in Ghana with Ghanaians in the UK, showed that among the native Ghanaians, fish (23\%) and soup and stews (23\%), were the major protein sources. ${ }^{17}$ This indicates that there is possibly a shift in the source of protein consumed by Ghanaian students, after coming to Korea. A change in dietary pattern was similarly observed by Pan et al., which found an increase in consumption of dairy products among Asian immigrants after moving to the USA. ${ }^{18}$

The Ghanaian MOH dietary guidelines recommends the daily energy intake from macronutrients is $30 \sim 50 \%$ from carbohydrates, $10 \sim 15 \%$ from fat, $5 \sim 10 \%$ from animalbased protein and $20 \sim 30 \%$ from plant-based protein. In the study by Gibson et al., where the native Ghanaians were compared with the UK-based Ghanaians, the daily energy intake among native Ghanaians was $61.5 \%$ from carbohydrate, $24.4 \%$ from fat and $14.1 \%$ from protein. ${ }^{17}$ In our study, 65, 22 and $12 \%$ came from carbohydrate, fat and protein, respectively. This indicates that there is an increased intake of energy from carbohydrate and fat and less from protein compared to the recommended intakes. The participants mentioned having meals either in the cafeteria or from Korean restaurants. This may have influenced the similarities between their diet patterns and the Korean diet. Our study participants were men, which maybe another factor that influenced eating-out patterns.
Additionally, similar to Korean diet patterns, the main dish in the study participants' diet consisted of rice or bread with meat or tuna. Having rice or bread may have contributed to $65 \%$ of their energy intake being from carbohydrates, which is also similar to the Korean diet pattern. The Ghanaian MOH recommends 3,091 kcal/day for males. In our study, the mean daily energy intake was $2,289.6 \pm 548.9 \mathrm{kcal}$, and $92.3 \%$ of the male students did not meet the RNI advocated by the FAO/WHO. The RNI values for various micronutrients, such as calcium, iron, zinc, vitamin A, vitamin B2, were also not met among our study participants. From literature, it has been established that skipping meals, particularly breakfast, does not result in an accurate energy compensation at subsequent meals and, consequently, daily energy intakes may decline. ${ }^{19}$

Meal skipping is the most common dietary practice reported among students including international students. ${ }^{20,21}$ In our study, breakfast skipping habits increased to an average of 3 times per week, after coming to Korea, which is consistent with findings from the works of, ${ }^{22}$ in which the majority of students stated they tended to skip breakfast due to tight lecture schedules. Participants in this study also cited time constraints as the main reason for skipping meals. This may be due to the acculturative process, which may require a period of adaptation to the new environment and an adjustment in time management. ${ }^{23}$

A comparison between meal skipping frequency and diet quality indicators, NAR and MAR, showed that several nutrients, such as vitamins $\mathrm{B} 1$ and vitamin $\mathrm{B} 2$, was significantly lower among subjects who skipped meals $\geq 7$ times/ week than those who skipped meals $<7$ times/week. This implies the possibility of a low-quality diet among Ghanaian students who skipped meals $\geq 7$ times/week. The link between dietary practices and the amount and quality of nutrients consumed is well-established. Gaowei et al. also found that college students who maintained good dietary practices before and after coming to Korea had a higher intake of food and nutrients than those who did not. ${ }^{24}$

The current study has limitations. The subjects had only resided in Korea for a short period of time. Therefore, an assessment of their, relatively, long-term changes in dietary behaviors was not done. Also, the intra-person variation in food and nutrient consumption, as obtained by a single 24$\mathrm{h}$ recall, may not be sufficient to assess the nutritional status of Ghanaian students. Body weights and heights 
were provided by the subjects and, therefore, may have been a source of bias on the part of some of the participants. Furthermore, the sample size was relatively small. In spite of the above limitations, this study is the first to have attempted to investigate the dietary patterns among Ghanaian international students and, to a large extent, students of African origin. Thus, the study is pivotal in providing baseline data for future nutrition researchers, who are interested in probing nutritional and dietary habits of international students, particularly those from West Africa.

In conclusion, we found that daily nutrient intakes were insufficient and did not meet the standards established by Ghana's MOH nutrient recommendations. Meal skipping practices were shown to differ significantly after coming to Korea. It was revealed that participants who skipped meals $\geq 7$ times/week had a lower diet quality than those who skipped meals $<7$ times/week. On the basis of our study findings, we recommend that nutrition education should be organized for the Ghanaian student community in Korea, using our study results as a template to draft a nutritional and culturally appropriate program.

\section{Summary}

The purpose of this study was to examine the dietary behavior and assess the nutritional status of Ghanaian students currently staying in Korea. This study is the first to have attempted to study the dietary patterns among Ghanaian international students. For the study, a total of 81 Ghanaian male students with an average age of $29.4 \pm 4.0$ years were sampled between May and June 2016. The study results showed that the daily intake for nutrients such as vitamins $\mathrm{A}$ and $\mathrm{C}$, iron, folate and energy requirements did not meet the daily RNI established by Ghana's MOH. Meal skipping behavior significantly increased among participants after coming to Korea. The study results also showed that the diet quality indicators, NAR and MAR, were lower among participants who skipped meals $\geq 7$ times/week compared to those who skipped meals $>7$ times/ week. These study findings imply a need for nutritional education, tailored based on the cultural practices, among Ghanaian students in Korea.

\section{References}

1. Ministry of Education, Overseas Korean Education Division.
Study Korea Project [Internet]. 2016 [cited 2017 Jul 19]. Available from: http://www.studyinKorea.go.Kr/en/sub/about/introduce. do.

2. Korea Immigration Service. Korea Immigration Service Statistics 2015 [Internet]. Gwacheon: Ministry of Justice; 2016 [cited 2016 Dec 16]. Available from: http://immigration.go.kr/HP/IMM80/ index.do.

3. Romero-Gwynn E, Gwynn D, Grivetti L, McDonald R, Stanford G, Turner B, West E, Williamson E. Dietary acculturation among Latinos of Mexican descent. Nutr Today 1993; 28(4): 6-12.

4. Lv N, Cason KL. Dietary pattern change and acculturation of Chinese Americans in Pennsylvania. J Am Diet Assoc2004; 104(5): 771-778.

5. Blundell J, Gumaste D, Handley R, Dye L. Diet, behaviour and cognitive functions: a psychobiological view. Scand J Nutr 2003; 47(2): 85-91.

6. Satia-Abouta J, Patterson RE, Neuhouser ML, Elder J. Dietary acculturation: applications to nutrition research and dietetics. J Am Diet Assoc 2002; 102(8): 1105-1118.

7. Gordon-Larsen P, Harris KM, Ward DS, Popkin BM; National Longitudinal Study of Adolescent Health. Acculturation and overweight-related behaviors among Hispanic immigrants to the US: the National Longitudinal Study of Adolescent Health. Soc Sci Med 2003; 57(11): 2023-2034.

8. Lee J, Gao RR, Kim JH. Acculturation and changes in dietary behavior and anthropometric measures among Chinese international students in South Korea. Nutr Res Pract 2015; 9(3): 304-312.

9. Akinyemi O, Ibraheem A. Assessment of nutritional status of queens college students of Lagos State, Nigeria. Pak J Nutr 2009; 8(7): 937-939.

10. McDonald JT, Kennedy S. Is migration to Canada associated with unhealthy weight gain? Overweight and obesity among Canada's immigrants. Soc Sci Med 2005; 61(12): 2469-2481.

11. Ben-David A, Lavee Y. Migration and marital distress: the case of Soviet immigrants. J Divorce Remarriage 1994; 21(3-4): 133-146.

12. Sam DL, Berry JW. The Cambridge handbook of acculturation psychology. Cambridge: Cambridge University Press; 2006.

13. Korean Statistical Information Service. The current situation of international student (2012-2015) [Internet]. Daejeon: Statistics Korea; 2015 [cited 2017 Apr 23]. Available from: http://kosis.kr/ statisticsList/statisticsList_01List.jsp?vwcd=MT_ZTITLE\&parmTabId=M_01_01.

14. Ministry of Health $(\mathrm{GH})$. Dietary and physical activity guidelines for Ghana [Internet]. Accra: Ministry of Health; 2009 [cited 2016 Dec 16]. Available from: http://alwag.org/education/courses/paguide.pdf.

15. Food and Agriculture Organization of the United Nations; World Health Organization. Human vitamin and mineral requirements. Rome: Food and Agriculture Organization of the United Nations; 2001.

16. Nti CA. Household dietary practices and family nutritional status in rural Ghana. Nutr Res Pract 2008; 2(1): 35-40.

17. Gibson R, Knight A, Asante M, Thomas J, Goff LM. Comparing dietary macronutrient composition and food sources between native and diasporic Ghanaian adults. Food Nutr Res 2015; 59(1): 27790 . 
18. Pan YL, Dixon Z, Himburg S, Huffman F. Asian students change their eating patterns after living in the United States. J Am Diet Assoc 1999; 99(1): 54-57.

19. Levitsky DA, Pacanowski CR. Effect of skipping breakfast on subsequent energy intake. Physiol Behav 2013; 119: 9-16.

20. Onyiriuka AN, Ibeawuchi AN, Onyiriuka RC. Assessment of eating habits among adolescent Nigerian urban secondary schoolgirls. Sri Lanka J Child Health 2013; 42(1): 20-26.

21. Abdull Hakim NH, Muniandy ND, Danish A. Nutritional status and eating practices among university students in selected uni- versities in Selangor, Malaysia. Asian J Clin Nutr 2012; 4(3): 7787.

22. Ackuaku-Dogbe EM, Abaidoo B. Breakfast eating habits among medical students. Ghana Med J 2014; 48(2): 66-70.

23. Papadaki A, Hondros G, A Scott J, Kapsokefalou M. Eating habits of university students living at, or away from home in Greece. Appetite 2007; 49(1): 169-176.

24. Gaowei, Kim S, Chang N, Kim KN. Dietary behavior and nutritional status among Chinese female college students residing in Korea. Korean J Nutr 2013; 46(2): 177-185. 